\title{
Three-Port DC-DC Converter for Stand-Alone Photovoltaic Systems
}

\author{
Yihua Hu, Member, IEEE, Weidong Xiao, Member Wenping Cao, Senor Member, IEEE, Bing Ji, \\ Member, IEEE, D. John Morrow, Member, IEEE
}

Abstract-System efficiency and cost effectiveness are of critical importance for photovoltaic (PV) systems. This paper addresses the two issues by developing a novel three-port DC-DC converter for stand-alone PV systems, based on an improved Flyback-Forward topology. It provides a compact single-unit solution with a combined feature of optimized maximum power point tracking (MPPT), high step-up ratio, galvanic isolation and multiple operating modes for domestic and aerospace applications. A theoretical analysis is conducted to analyze the operating modes followed by simulation and experimental work.

The paper is focused on a comprehensive modulation strategy utilizing both PWM and phase-shifted control that satisfies the requirement of PV power systems to achieve MPPT and output voltage regulation. A $250 \mathrm{~W}$ converter was designed and prototyped to provide experimental verification in term of system integration and high conversion efficiency.

Index Terms - DC-DC power conversion, maximum power point tracking, phase shift, photovoltaic power system, voltage control.

\section{INTRODUCTION}

Q OLAR energy is a primary and renewable source of $N$ energy. As the cost of photovoltaic (PV) panels is seen to reduce continuously, $\mathrm{PV}$-based power generation is gaining in

Manuscript received February 7, 2014; revised March 19, 2014; accepted May 30, 2014.

$\mathrm{Y}$. $\mathrm{Hu}$ is with the Department of Electronic and Electrical Engineering, University of Strathclyde, Glasgow, G1 1XQ, U.K.

W. Xiao is with Faculty of Science and Technology, Masdar Institute, Abu Dhabi, UAE.

W. Cao and J. Morrow are with the School of Electronics, Electrical Engineering and Computer Science, Queen's University Belfast, Belfast, BT9 5AH, U.K. (e-mail: w.cao@qub.ac.uk).

B. Ji is with the School of Electrical and Electronic Engineering, Newcastle University, Newcastle upon Tyne, NE1 7RU, U.K.

Color versions of one or more of the figures in this paper are available online at http://ieeexplore.ieee.org. popularity for both grid-connected and stand-alone systems [1]-[5]. Currently, the global installation is over $40 \mathrm{GW}$ and increases at an annual rate of 50\% since 2005 [6].

Stand-alone systems are independent of utility grids and commonly employed for satellites, space stations, unmanned aerial vehicles (UAV) and domestic applications [7]-[10]. Such systems require storage elements to accommodate the intermittent generation of solar energy [11]-[15]. Over the years, research effort has been directed toward improving the power conversion efficiency as well as the power density by weight (PDW) and the power density by volume (PDV) [16][17].

Traditionally, the two-port topology utilizes the dual active bridges (DAB) [18]-[21] and the half or full bridges can support the multiport structure to some extent [22]-[25]. A combination of Flyback-Forward converter with full bridge has shown some advantages in zero voltage switching (ZVS) and high conversion ratio for fuel cell applications [26]. A modified half bridge converter is reported in [27] which consists of one PV input port, one bidirectional battery port, and an isolated output for satellite applications. However, in these converters, a multi-input-multi-output (MIMO) solution is generally difficult to achieve for power electronic applications.

In theory, multiple-input converters (e.g. three-port converters) can provide a single-unit solution interfacing multiple energy sources and common loads [28]-[30]. They perform better than traditional two-port converters due to their lower part count and smaller converter size. In particular, the isolated three-port converter (ITPC) has become an attractive topology for various applications owing to their multiple energy source connection, compact structure and low cost [31]-[33]. In this topology, a simple power flow management scheme can be used since the control function is centralized. A high-frequency transformer can provide galvanic isolation and flexible voltage conversion ratio. The ITPC is usually 
integrated into an individual converter such as forward, push-pull, full bridge, and Flyback converters [34][35].

The ITPC utilizes the triple active bridges (TAB) with inherent features of power controllability and ZVS. Their soft-switching performance can be improved if two series-resonant tanks are implemented [36]. An advanced modulation strategy is reported in [37] which incorporates a phase shift (PS) and a PWM to extend the operating range of ZVS. Nonetheless, the TAB topology suffers from the circuit complexity using three active full bridges or half bridges and the power loss caused by reactive power circulation. Therefore a Buck-Boost converter is proposed [38] to integrate a three-port topology in the half bridge and to decompose the multivariable control problem into a series of independent single-loop subsystems. By doing so, the power flow in each loop can be independently controlled. The system is suitable for PV-battery applications since one converter interfaces the three components of the PV array, battery, and loads. However, in each energy transfer state, current passes through at least five inductor windings, especially under high switching frequency conditions, giving rise to power loss; its peak efficiency is less than $90 \%$ and its power capability is limited by the transformer design, making it impossible for current sharing.

Based on these topologies, a new three-port DC-DC converter is developed in this paper to combine a new ITPC topology and an improved control strategy, and to achieve decoupled port control, flexible power flow and high power capability while still making the system simple and cheap.

\section{TOPOLOGY AND OPERATION}

The proposed converter topology is illustrated in Fig. 1. The main switches $S_{1}$ and $S_{2}$ transfer the energy from the PV to the battery or load, and can work in either interleaved or synchronous mode. The switches $S_{3}$ and $S_{4}$ are operated in the interleaved mode to transfer energy from source to load. $L_{l}$ and $L_{2}$ are two coupled inductors whose primary winding $\left(n_{l}\right)$ is employed as a filter and the secondary windings $\left(n_{2}\right)$ are connected in series to achieve a high output voltage gain. $L_{L K}$ is the leakage inductance of the two coupled inductors and $N$ is the turns ratio from $n_{2} / n_{1} . C_{S 1}, C_{S 2}, C_{S 3}$ and $C_{S 4}$ are the parasitic capacitors of the main switches $S_{1}, S_{2}, S_{3}$ and $S_{4}$, respectively.

There are three operational modes for the converter, as illustrated in Fig. 2 [39]. In mode 1, the PV array supplies power to load and possibly also to the battery, corresponding to the daytime operation of the PV system. Two $180^{\circ}$ out-of-phase gate signals with the same duty ratio $(D)$ are applied to $S_{I}$ and $S_{2}$ while $S_{3}$ and $S_{4}$ remain in a synchronous rectification state. When in the steady-state operation, there are four states in one switching period, of which the equivalent circuits are shown in Fig. 3. The steady-state waveforms of the four states are depicted in

Fig. 4, where $V_{G S 1}, V_{G S 2}, V_{G S 3}$ and $V_{G S 4}$ are the gate drive signals, $V_{d s 1}$ and $V_{d s 2}$ are the voltage stresses of $S_{1}$ and $S_{2}, i_{L 1 a}$ and $i_{L 2 a}$ are the currents through $L_{l a}$ and $L_{2 a}$, respectively. $i_{B}$ is the current through the battery, $i_{s I}$ is the current through $S_{I}, v_{D o l}$ is the voltage stress of the output diode $D_{o l}$, and $i_{D o l}$ is the current through $D_{o l}$.

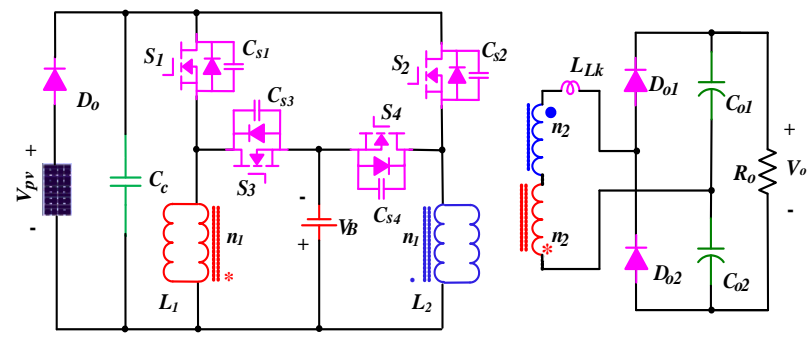

Fig. 1. The proposed converter topology.
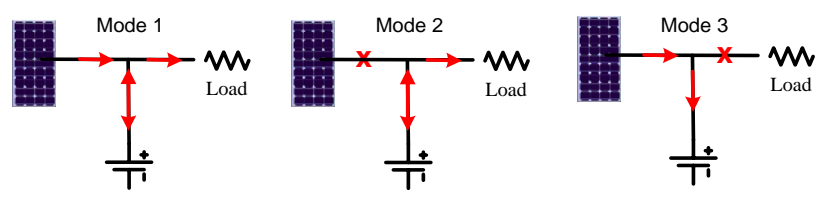

Fig. 2. Three operation modes of the proposed converter.
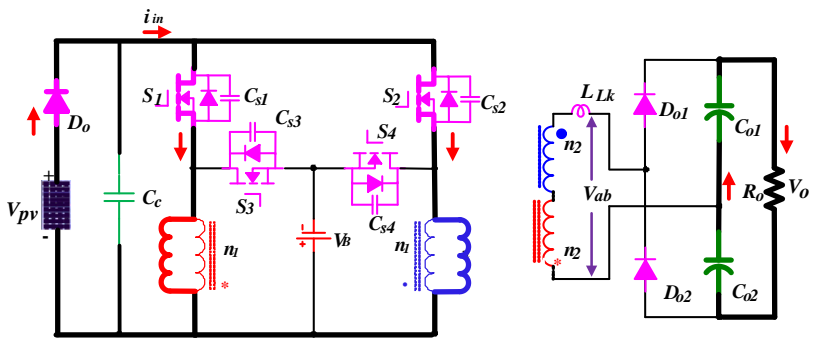

(a)

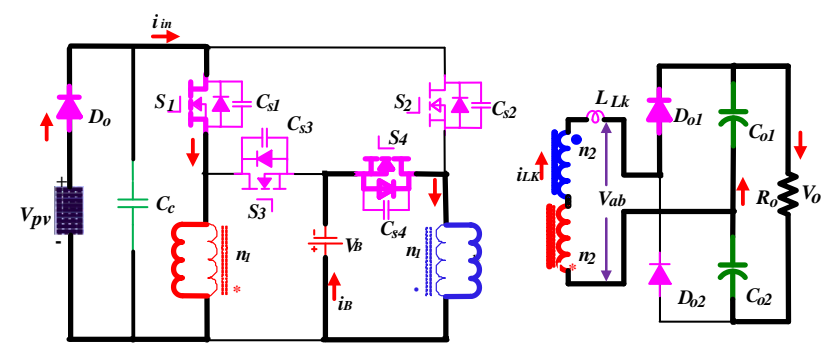

(b) 


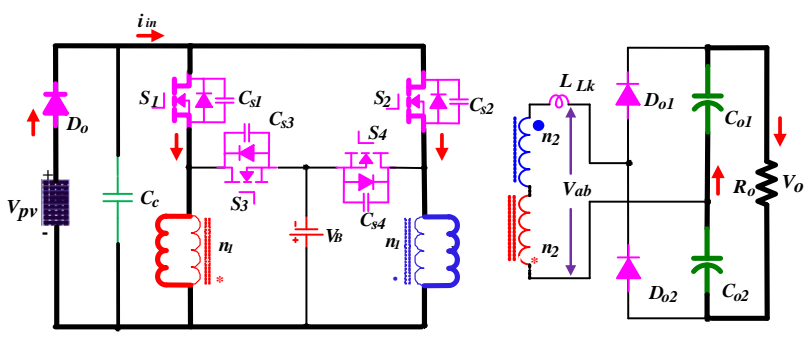

(c)

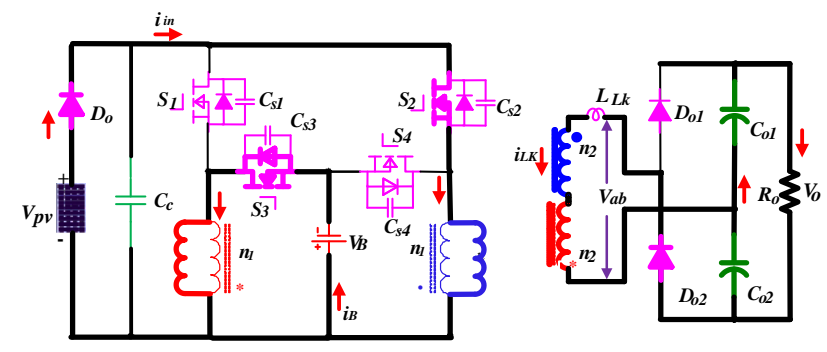

(d)

Fig. 3. Four operating states of the proposed converter in mode 1.

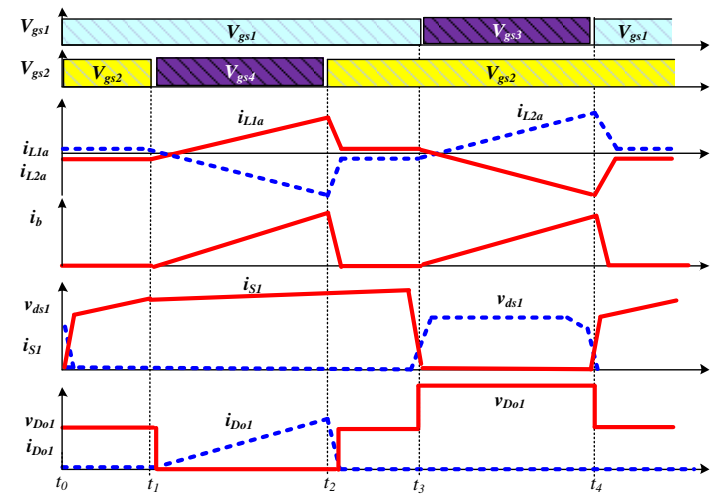

Fig. 4. Waveforms of the proposed converter under mode 1.

State $1\left[t_{0}-t_{1}\right]$ : The main switches $S_{1}$ and $S_{2}$ are both in turn-on state before $t_{0}$. The two coupled inductors work in the flyback state to store energy from the PV array. The output rectifier diodes $D_{o 1}$ and $D_{o 2}$ are both reverse-biased. The energy stored in the secondary output capacitors $C_{o 1}$ and $C_{o 2}$ transfers to the load.

State $2\left[t_{1}-t_{2}\right]$ : At $t_{1}, S_{2}$ turns OFF, $S_{4}$ turns ON, while the diodes $D_{o l}$ is ON. The primary side of the coupled inductor $L_{2}$ charges the battery through $S_{4}$. During this state, $L_{l}$ operates in the forward mode and $L_{2}$ operates in the flyback mode to transfer energy to the load. When $S_{1}$ turns on and $S_{2}$ turns off, the primary voltage of the coupled inductor $L_{l}$ is $V_{\mathrm{pv}}$ and the voltage on $L_{2}$ is $-V_{B}$.

According to the voltage balance law,

$$
D V_{P V}=(1-D) V_{B}
$$

$$
V_{a b}=N \frac{1-D}{D} V_{B}-N\left(-V_{B}\right)=\frac{N V_{B}}{D}
$$

State $3\left[t_{2}-t_{3}\right]$ : At $t_{2}, S_{2}$ turns $\mathrm{ON}$, which forces the two coupled inductors work in the flyback state to store energy and $D_{o 2}$ is reverse-biased. The energy stored in $C_{o 1}$ and $C_{o 2}$ transfers to the load. At $t_{3}$, the leakage inductor current decreases to zero and the diode $D_{o l}$ turns OFF.

State $4\left[t_{3}-t_{4}\right]$ : At $t_{3}, S_{1}$ turns $\mathrm{OFF}$ and $S_{3}$ turns ON, which turns $D_{o 2}$ ON. The primary side of coupled inductor $L_{l}$ charges the battery through $S_{3}$. During this state, $L_{2}$ operates in the forward mode and $L_{l}$ operates in the flyback mode to transfer energy to the load. When $S_{1}$ turns $\mathrm{ON}$ and $D_{o 2}$ turns OFF, followed by a new switching period.

In mode 2 , the battery supplies power to the load, as shown in Fig. 5(a), indicating the nighttime operation of the stand-alone system. The circuit works as the Flyback-Forward converter, where $S_{3}$ and $S_{4}$ are the main switches, $C_{c}, S_{1}$ and $S_{2}$ form an active clamp circuit. When the load is disconnected, the stand-alone system enters into mode 3 . The PV array charges battery without energy transferred to the load due to the opposite series connected structure of the coupled inductor (see Fig. 5b). $S_{1}$ and $S_{2}$ work simultaneously and the topology is equivalent to two paralleled Buck-Boost converters.
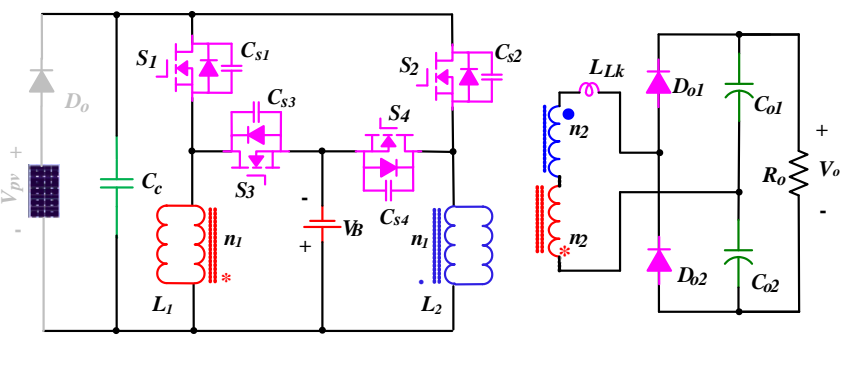

(a) Mode 2

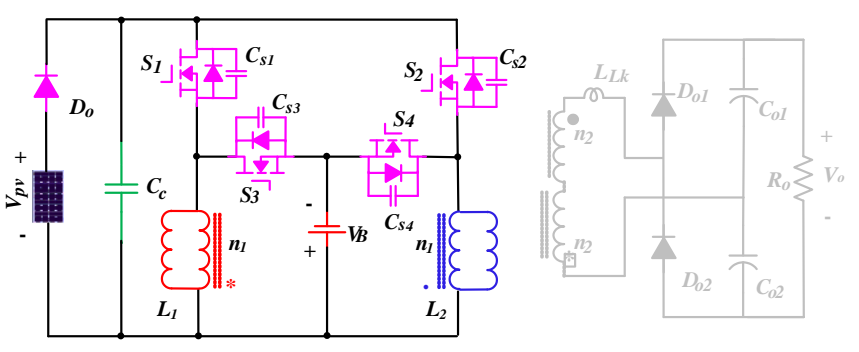

(b) Mode 3

Fig. 5. Converter operating modes 2 and 3.

\section{Performance AnAlysis And FEedBack LoOP DESIGN}

In order to realize flexible energy flow control, the modulation strategy is proposed to combine PWM with PS 
schemes. Firstly, the relationship of voltage gains with duty ratio and PS needs to be derived. In the following analysis, $S_{I}$ and $S_{2}$ have the same duty ratio $D$, whilst $S_{3}$ and $S_{4}$ share another duty ratio. The gate signals for $S_{1}$ and $S_{3}$ are complementary, and so are $S_{2}$ and $S_{4}$.

\section{A. Analysis of Circuit Performance for $D \geq 0.5$}

When the duty cycle $D \geq 0.5$, there are five operating cases which need to be analyzed, as shown in Fig. 6.

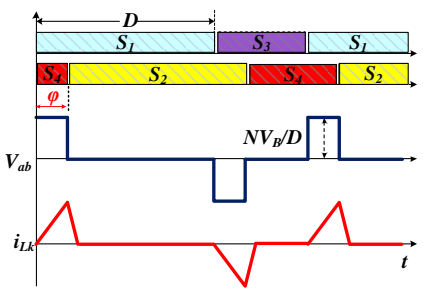

(a) Case 1

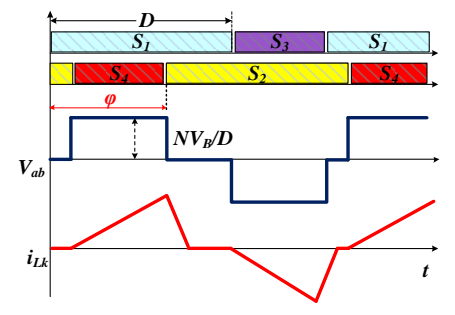

(c) Case 3

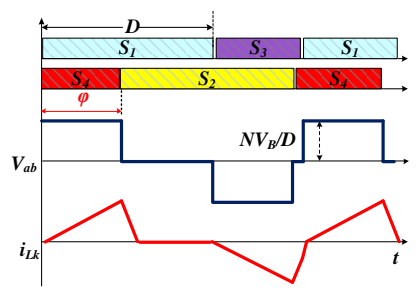

(b) Case 2

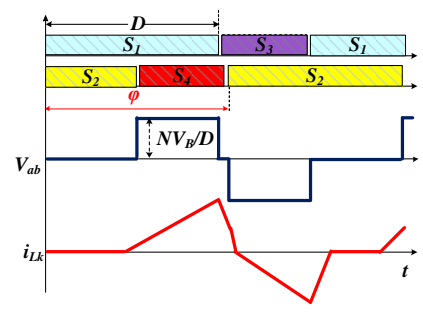

(d) Case 4

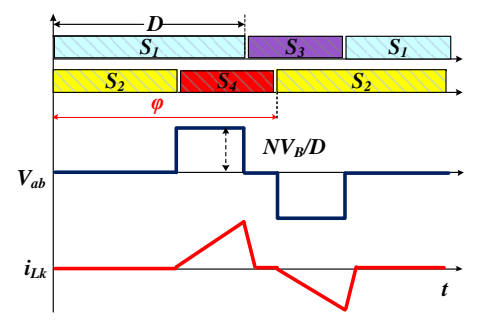

(e) Case 5

Fig. 6. Five operational cases for $D \geq 0.5$.

In case 1, the phase shift angle is between 0 and $\varphi_{\text {critl }}$. From the waveform of the leakage inductor current, the secondary side of the coupled inductor is equivalent to a discontinuous conduction mode (DCM) of a Buck converter. When $\varphi=\varphi_{\text {critl }}$, the current pulses $A$ and $B$ is in a boundary conduction mode, as shown in Fig. 7.

For pulse $A$, the current decreases to the negative peak value and increases to zero at the time of $(1-D) T_{s}$. The decrement time is equal to $T_{s} \varphi_{\text {crit } 1} / 2 \pi$ and the increment time is $\left(1-D-\varphi_{\text {crit } 1} / 2 \pi\right) T_{s}$. Following the voltage-second balance (Eq. 3), the critical phase angle can be determined by Eq. 4 .
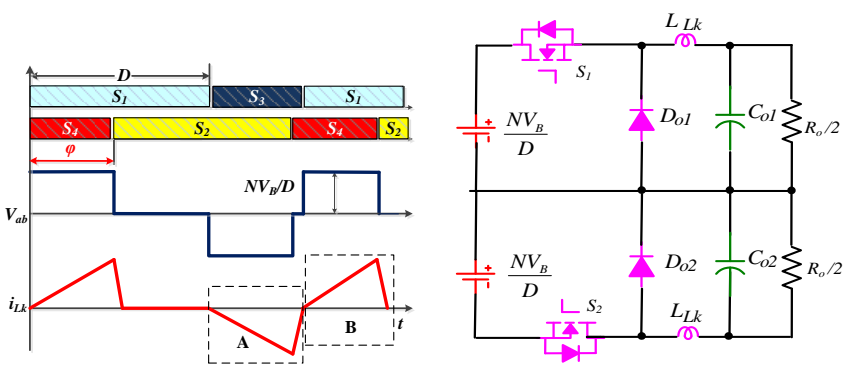

(a) Signal waveforms (b) Equivalent circuit at $\varphi=\varphi_{\text {crit } 1}$

Fig. 7. System operation in Case 1.

$$
\begin{gathered}
\frac{N V_{B}}{D} \cdot \frac{\varphi_{\text {crit } 1}}{2 \pi} \cdot T_{s}=\frac{V_{o}}{2}\left(1-D-\frac{\varphi_{\text {crit } 1}}{2 \pi}\right) T_{s} \\
\varphi_{\text {crit } 1}=\pi \cdot D \cdot(1-D) \cdot \frac{V_{\text {out }}}{N \cdot V_{B}}
\end{gathered}
$$

The secondary side of the coupled inductor is equivalent to two Buck converters connected in parallel at the DCM operational condition. The corresponding equivalent duty ratio of the Buck converter is $\varphi / 2 \pi$. Provided the voltage gain of the Buck converter in DCM, the output voltage is given by:

$$
V_{o}=2 \cdot \frac{2}{1+\sqrt{1+\frac{4 \cdot 2 L_{k}}{R_{o} \cdot T_{s} \cdot(\varphi / 2 \pi)^{2} / 2}}} \cdot \frac{N V_{B}}{D}
$$

In case 2 , the phase shift angle is between $\varphi_{\text {critl }}$ and $\varphi_{\text {crit2. }} . \varphi_{\text {crit2 }}$ is the transition point from a continuous conduction mode (CCM) to a DCM, which can be determined by Eq. 6. The voltage equations at $\varphi_{\text {critl }}$ and $\varphi_{\text {crit }}$ are derived by Eqs. 7 and 8.

$$
\begin{gathered}
\varphi_{\text {crit } 2}=\frac{4 \pi \cdot(1-D)}{D} \cdot \frac{N \cdot V_{B}}{V_{\text {out }}} \\
\frac{N V_{B}}{D L_{k}}(1-D)=\frac{V_{o}}{2 L_{k}} \frac{\varphi_{\text {crit } 2}}{2 \pi} \\
\frac{N V_{B}}{D L_{k}} \frac{\varphi_{\text {crit } 1}}{2 \pi}=\frac{V_{o}}{2 L_{k}}(1-D)
\end{gathered}
$$

In case 3 , the angle shifts from $\varphi_{\text {crit } 2}$ to $\varphi_{\text {crit3 }}$. The duty ratio of the secondary side of the Buck converter stays constant, and the voltage gain reaches the highest. Therefore, the critical point, $\varphi_{\text {crit }}$, and the corresponding voltage can be calculated by Eqs. 9 and 10. $\varphi_{\text {crits }}$ is the boundary point between DCM and CCM. With the increase in the PS angle, the voltage declines. In this case, the output voltage cannot be controlled by PS, as suggested by Eq. 11 .

$$
\begin{gathered}
\varphi_{\text {crit } 3}=2 \pi-\varphi_{\text {crit } 2} \\
\frac{N V_{B} / D}{L_{k}}(1-D)=\frac{V_{o}}{2 L_{k}}\left(1-\frac{\varphi_{\text {crit } 3}}{2 \pi}\right)
\end{gathered}
$$




$$
V_{o}=2 \cdot \frac{2}{1+\sqrt{1+\frac{4 \cdot 2 L_{k}}{R_{o} \cdot T_{s} \cdot(1-D)^{2} / 2}}} \cdot \frac{N V_{B}}{D}
$$

In case 4, the PS angle ranges from $\varphi_{\text {crit }}$ to $\varphi_{\text {crit }}$. The leakage inductor current is still higher than zero before next voltage pulse. $\varphi_{\text {crit }}$ is the boundary point between DCM and CCM. The critical point, $\varphi_{\text {crit }}$ and the corresponding voltage can be expressed as Eqs. 12 and 13.

$$
\begin{gathered}
\varphi_{\text {crit } 4}=2 \pi-\varphi_{\text {crit } 1} \\
\frac{N V}{D L_{k}}\left(1-\frac{\varphi_{\text {crit } 4}}{2 \pi}\right)=\frac{V_{o}}{2 L_{k}}(1-D)
\end{gathered}
$$

In case 5, the phase shift angle increases from $\varphi_{\text {crit }}$ to $2 \pi$. The duty ratio of the secondary side Buck converter is $1-\varphi / 2 \pi$. The output voltage can be given by

$$
V_{o}=2 \cdot \frac{2}{1+\sqrt{1+\frac{4 \cdot 2 L_{k}}{R_{o} \cdot T_{s} \cdot(1-\varphi / 2 \pi)^{2} / 2}}} \cdot \frac{N V_{B}}{D}
$$

\section{B. Analysis of Circuit Performance for $D<0.5$}

Similarly, there are five operating cases for $D<0.5$. The respective waveforms are shown in Fig. 8.

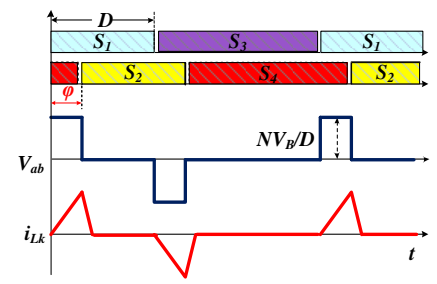

(a) Case 1

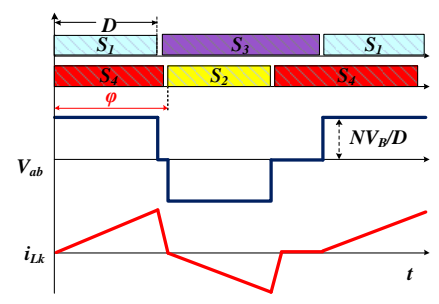

(c) Case 3

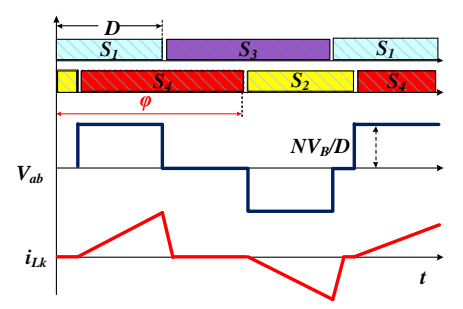

(e) Case 5

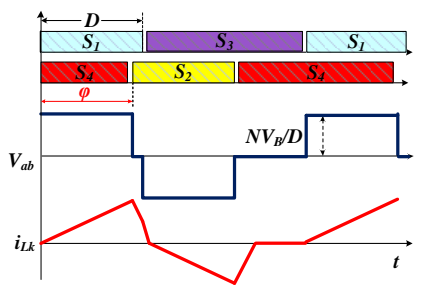

(b) Case 2

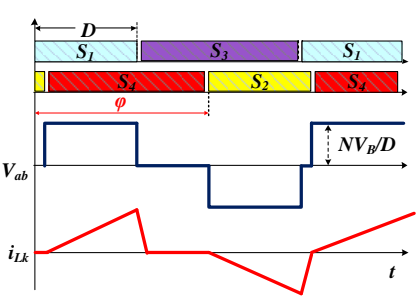

(d) Case 4
Fig. 8. Five cases under $D<0.5$.
In Case $1\left(0<\varphi<\varphi_{\text {crit }}\right)$, considering the waveform of the leakage inductor current, the secondary side of the coupled inductor is equivalent to a DCM Buck converter, the corresponding duty ratio is $D=\varphi / 2 \pi$. Thus the critical angle and the output voltage are:

$$
\begin{gathered}
\varphi_{\text {crit } 1}=\pi \cdot D^{2} \cdot \frac{V_{o}}{N \cdot V_{B}} \\
V_{o}=2 \cdot \frac{2}{1+\sqrt{1+\frac{4 \cdot 2 L_{k}}{R_{o} \cdot T_{s} \cdot(\varphi / 2 \pi)^{2} / 2}}} \cdot \frac{N V_{B}}{D}
\end{gathered}
$$

In case $2\left(\varphi_{\text {critl }}<\varphi<\varphi_{\text {crit } 2}\right)$, the leakage inductor current is still above zero. The system equations can be expressed as

$$
\begin{aligned}
& \varphi_{\text {crit } 2}=4 \pi \cdot \frac{N \cdot V_{B}}{V_{o}} \\
& \frac{N V_{B}}{D L_{k}} \cdot \frac{\varphi_{\text {crit } 1}}{2 \pi}=\frac{V_{o}}{2 L_{k}} \cdot D \\
& \frac{N V_{B}}{D L_{k}} \cdot D=\frac{V_{o}}{2 L_{k}} \frac{\varphi_{\text {crit } 2}}{2 \pi}
\end{aligned}
$$

In case $3\left(\varphi_{\text {crit } 2}<\varphi<\varphi_{\text {crit }}\right)$, the duty ratio of the secondary winding is equal to $D$. The system equations are

$$
\begin{gathered}
\varphi_{\text {crit } 3}=2 \pi-\varphi_{\text {crit } 2} \\
\frac{N V_{B}}{D L_{k}} \cdot D=\frac{V_{o}}{2 L_{k}}\left(1-\frac{\varphi_{c r i t 3}}{2 \pi}\right) \\
V_{o}=2 \cdot \frac{2}{1+\sqrt{1+\frac{4 \cdot 2 L_{k}}{R_{o} \cdot T_{s} \cdot D^{2} / 2}}} \cdot \frac{N V_{B}}{D}
\end{gathered}
$$

In case 4 ( $\left.\varphi_{\text {crit } 3}<\varphi<\varphi_{\text {crit }}\right)$, the leakage inductor current is still above zero. The system equations can be expressed as

$$
\begin{gathered}
\varphi_{\text {crit } 4}=2 \pi-\varphi_{\text {crit } 1} \\
\frac{N V_{B}}{D L_{k}} \cdot\left(1-\frac{\varphi_{\text {crit } 4}}{2 \pi}\right)=\frac{V_{o}}{2 L_{k}} \cdot D
\end{gathered}
$$

In case $5\left(\varphi_{\text {crit }}<\varphi<2 \pi\right)$, the duty ratio of the secondary winding is $1-\varphi / 2 \pi$. The output voltage is derived by

$$
V_{o}=2 \cdot \frac{2}{1+\sqrt{1+\frac{4 \cdot 2 L_{k}}{R_{o} \cdot T_{s} \cdot(1-\varphi / 2 \pi)^{2} / 2}}} \cdot \frac{N V_{B}}{D}
$$

From the above derivations, $D$ is the control variable to balance the PV voltage and battery voltage and $\varphi$ is employed to control the secondary output voltage. The two-freedom control makes it flexible to control the PV, battery and load. One condition should be applied to achieve decoupled control 
performance, which can be expressed as $0<\varphi<\varphi_{\text {crit } 2}$ and $\varphi_{\text {crit } 3}$ $<\varphi<2 \pi$. If this is not satisfied, the secondary output voltage is dictated by the switching duty cycle instead of the phase shift angle as presented in Eqs. 11 and 22. In mode 1, the primary side is equivalent to an interleaved Buck-Boost converter operating in the continuous conduction mode due to the asymmetrical complementary operation of the switching devices $\left(S_{1}, S_{3}\right)$ and $\left(S_{2}, S_{4}\right)$. The operation of the secondary side follows a Buck converter whose duty ratio can be controlled by phase shift angle except for case 3.

\section{Feedback Loop Design}

In mode $1, S_{1}$ and $S_{3}$ complementarily conduct, and the on/off operation of $S_{2}$ and $S_{4}$ is complementary. When the output power of the PV array is lower than the load power, the battery should supply the difference. The primary side of the proposed converter is equivalent to a bidirectional Buck-Boost converter, while the secondary side is a Buck converter in discontinuous conduction mode. The output voltage can be controlled by PS on the primary side bridge arm, which can be approximated to adjust the duty cycle of Buck converter of secondary side to realize output voltage regulation. The control block diagram of the proposed control scheme is further illustrated in Fig. 9.

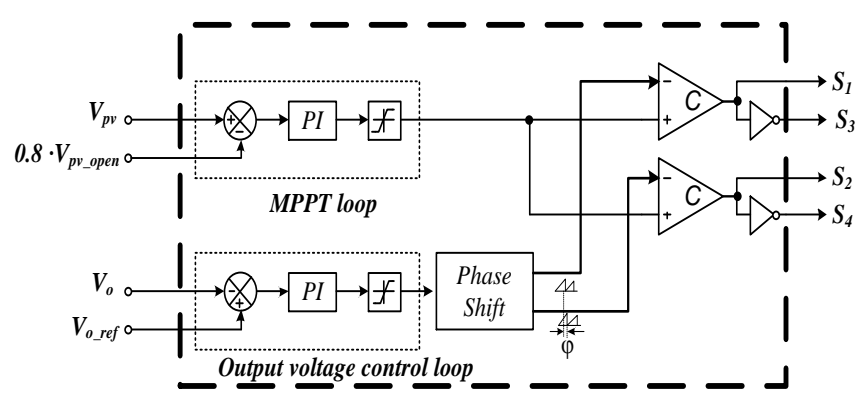

Fig. 9. Diagram of the proposed control scheme.

The maximum power point tracking (MPPT) can be implemented by adjusting the duty cycle of switching devices. In the MPPT loop, the PV voltage is regulated to follow an optimal operating point, which is initially assigned to $80 \%$ of the open-circuit voltage of the PV array. This point can be determined by the outer MPP Tracker, as previously reported in [40]. Moreover, the PV voltage regulation loop is used to improve the MPPT performance [41]. In the output voltage control loop shown in Fig. 9, the phase angle of the modulation carrier is the control variable, which regulates the output voltage to follow the expected voltage. Because of the block diode in the PV input, mode 1 can be switched to mode 2 by changing $D \geq 0.5$ to $D<0.5$. Likewise, the modes can be switched from 1 to 3 by controlling the phase shift angle between $S_{l}$ and $S_{2}$. These transitions are smoothly achieved by the proposed control method.

\section{Design Considerations}

In the MPPT control, the PV energy transfers to the battery, the circuit is a Buck-Boost converter. The maximum load voltage at idea conditions can be expressed as

$$
V_{o(\max )}=\frac{2 N}{D} V_{B}
$$

In order to realize the decoupling of load voltage and MPPT control, the output voltage (in Eq. 26) should be larger than the reference load voltage to gain a large phase shift angle.

Design considerations can be listed as follows: (i) Confirm PV array MPP voltage and corresponding control region and battery; Calculate $D$ working region. (ii) Choose the turns ratio of the coupled inductor to guarantee a large phase shift angle, following Eq. 27.

$$
N=\frac{V_{o_{-} a i m}(1+\alpha)}{2 V_{B}} D
$$

where $\alpha$ is the phase shift angle coefficient, and $V_{o_{-} a i m}$ is the reference output voltage.

Fig. 10 illustrates a design case study for a $16 \mathrm{~V}$ (open voltage) PV module with $12 \mathrm{~V}$ battery voltage and $80 \mathrm{~V}$ reference output voltage. In this case, by choosing 2 as the coupled inductor turns ratio, a phase shift control margin of at least $18 \mathrm{~V}$ can be achieved.

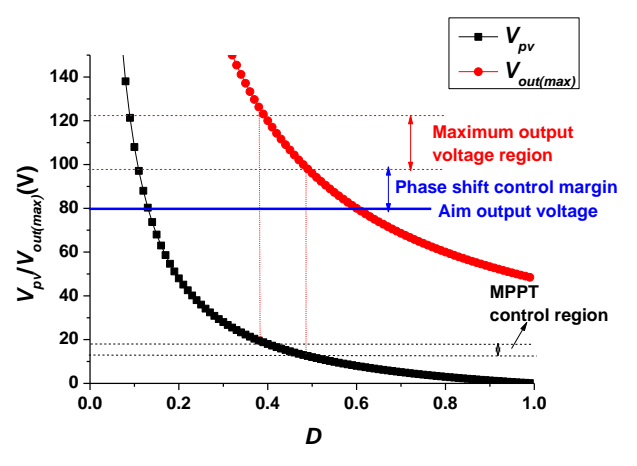

Fig. 10. Design considerations. 


\section{SIMULATION AND EXPERIMENTAL RESULTS}

Both simulation and experimental tests are conducted to evaluate the proposed converter topology and control scheme. The system parameters for evaluation are listed in Table I.

TABLE I PARAMETERS OF THE PROTOTYPE CONVERTER

\begin{tabular}{|l|l|}
\hline \multicolumn{1}{|c|}{ Parameter } & Product/Value \\
\hline $\mathrm{D}_{01}-\mathrm{D}_{02}$ & BYW99W200 \\
\hline $\mathrm{S}_{1}-\mathrm{S}_{4}$ & FDP047AN \\
\hline $\mathrm{N}=\mathrm{n}_{2}: \mathrm{n}_{1}$ & $2: 1$ \\
\hline $\mathrm{C}_{\mathrm{c}}$ & $100 \mathrm{~V} / 100 \mu \mathrm{F}$ \\
\hline $\mathrm{C}_{\mathrm{o} 1}-\mathrm{C}_{\mathrm{o} 2}$ & $250 \mathrm{~V} / 470 \mu \mathrm{F}$ \\
\hline Switching frequency & $20 \mathrm{kHz}$ \\
\hline Battery voltage & $12 \mathrm{~V}$ \\
\hline Output voltage & $80 \mathrm{~V}$ \\
\hline Step-up ratio & 6.25 \\
\hline
\end{tabular}

\section{A. Simulation Tests}

Simulation work is carried out in the PSIM environment to establish the relationship of the phase angle shift and output voltage, and to test the proposed control scheme including MPPT and output voltage control.

Fig. 11(a) and (b) show the phase angle shift control and output voltage response at $D \geq 0.5$ and $D<0.5$ conditions. The phase angle is divided into five portions in accordance with five cases in the theoretical analysis. In Fig. 11(a), the output voltage is controllable for cases $1,2,4$, and 5 by the phase angle but it is not in case 3 . When $D<0.5$ (Fig. 11b), the relationship becomes more linear than Fig. 11(a). As shown Fig. 11(c), the PV voltage is regulated to $12.8 \mathrm{~V}$, which represents the MPP. The output voltage is controlled at $80 \mathrm{~V}$ as expected. Fig. 11(d) presents waveforms of the gate signals and secondary-side inductance current. At $45 \mathrm{~ms}$, the load resistance is suddenly reduced from $100 \Omega$ to $40 \Omega$ (perturbation); the output voltage drops to $73 \mathrm{~V}$, and recovers to $80 \mathrm{~V}$ after $15 \mathrm{~ms}$ adjustment, as presented in Fig. 11(e). It is also seen in Fig. 11(f) that the PV array voltage recovers to the MPP voltage after $1 \mathrm{~ms}$ adjustment when subjected to an input power step change from $500 \mathrm{~W} / \mathrm{m}^{2}$ to $1000 \mathrm{~W} / \mathrm{m}^{2}$ (perturbation) at $40 \mathrm{~ms}$.

\section{B. Experimental Tests}

The proposed converter topology and control scheme are implemented in a $250 \mathrm{~W}$ prototype (see Fig. 12) with a Texas Instruments TMS320F28335 controller. Experimental tests are conducted with a PV array simulator (Agilent Technology E4360A) to obtain the steady-state waveforms of the proposed converter under different operating conditions.
Fig. 13 presents waveforms of the input current $\left(i_{\text {in }}\right)$, battery current $\left(i_{B}\right)$ and the secondary side of the coupled inductor current $\left(i_{L K}\right)$, for the phase angle shift under five different cases. Cases 1 and 5 have identical characteristics, and so do cases 2 and 4. Fig. 14 shows the regulation performance of the converter. As can be seen, the output voltage is controlled at constant $80 \mathrm{~V}$ using the phase angle shift modulation. Meanwhile, the duty cycle control of PWM regulates the PV voltage at $12.8 \mathrm{~V}$, which corresponds to the MPP of the PV array simulator. Fig.13(c) shows the switching device waveforms where the zero voltage soft switching is realized.

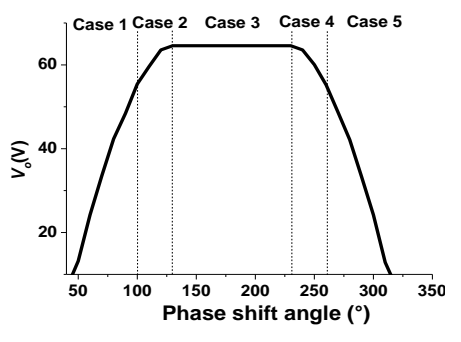

(a) $D>0.5(D=0.66)$

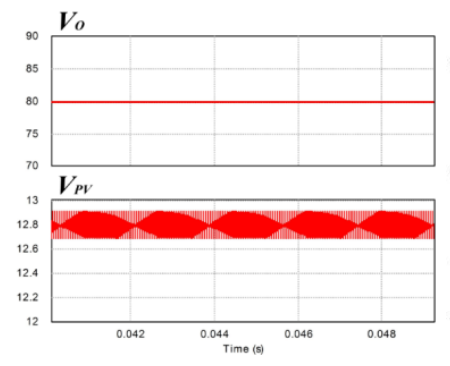

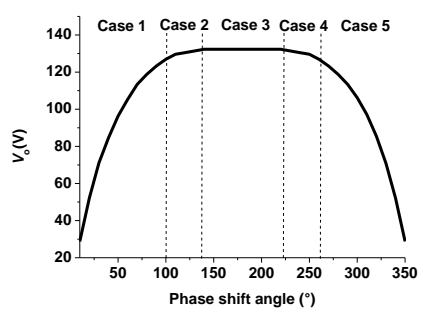

(b) $D<0.5(D=0.33)$

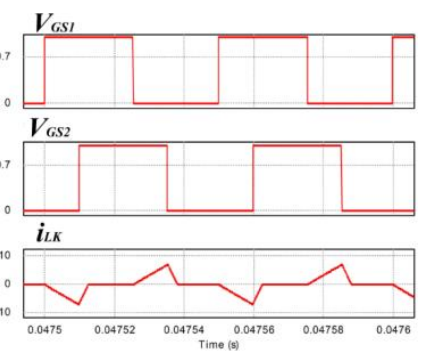

(c) Output and PV voltages (d) $2^{\text {nd }}$-side current of the coupled inductor

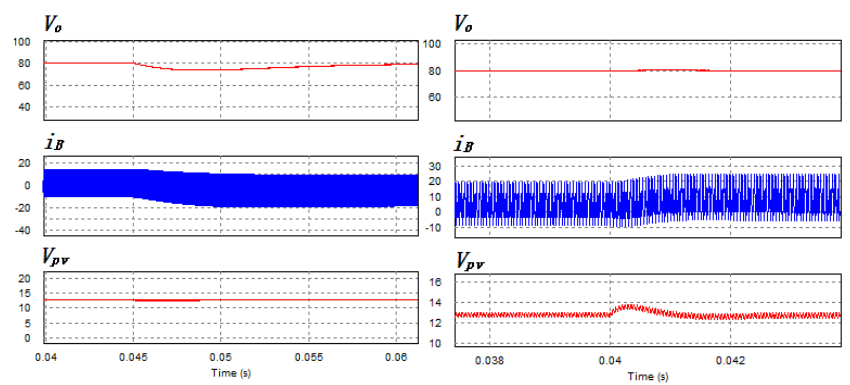

(e) Response to the load step (f) Response to the power step

Fig. 11. Simulation results of the proposed control scheme.

Modes 2-3 are also tested with the results presented in Figs. 15 and 16. Fig. 15 shows the output waveforms with the phase shift for different cases for $D<0.5$. Under this condition, the battery discharges energy to the load and the blocking diode stops the reverse current flowing into the PV array (mode 2). In mode 3 (Fig. 16), $S_{1}$ and $S_{2}$ have the same duty ratio without a phase angle shift. The power is only transferred from the PV to 
the battery to realize charging. The output voltage becomes zero due to the reverse series connection of the secondary side of the coupled inductor.

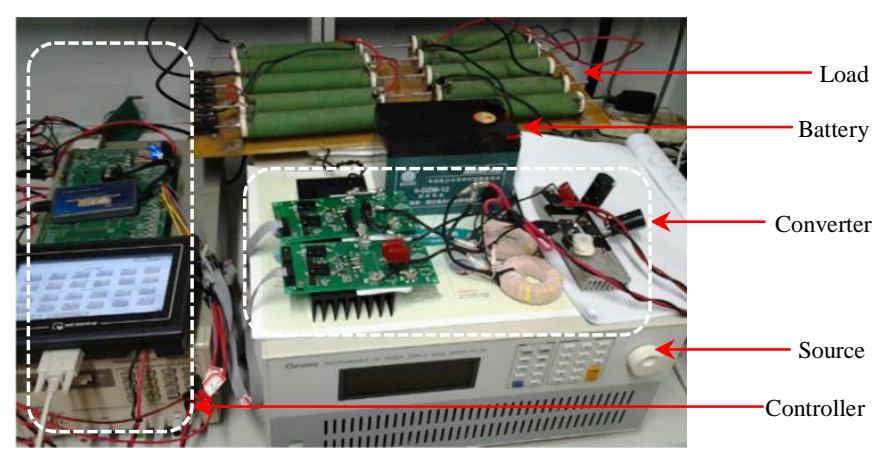

Fig. 12. Experimental setup of the proposed converter test system.

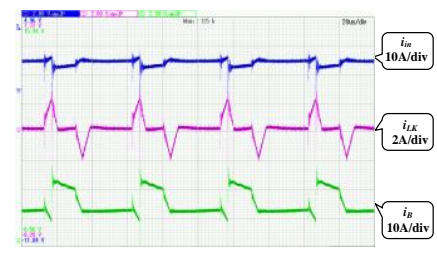

(a) Case $1\left(\varphi=30^{\circ}\right)$

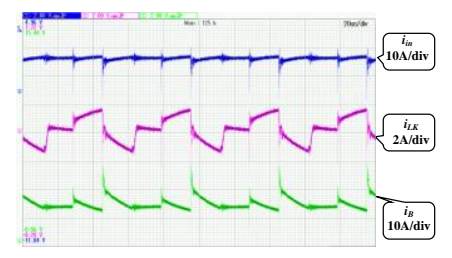

(b) Case $2\left(\varphi=120^{\circ}\right)$

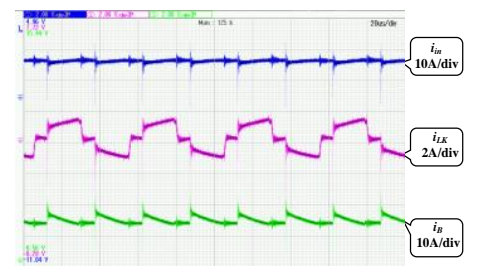

(c) Case $3\left(\varphi=180^{\circ}\right)$

Fig. 13. Current waveforms for different cases ( $>0.5$ mode 1).

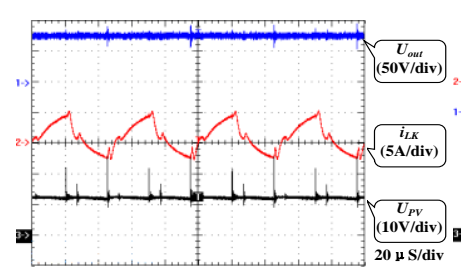

(a) Output voltage

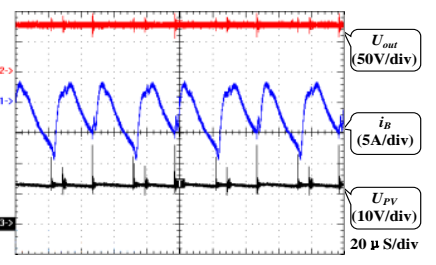

(b) PV voltage

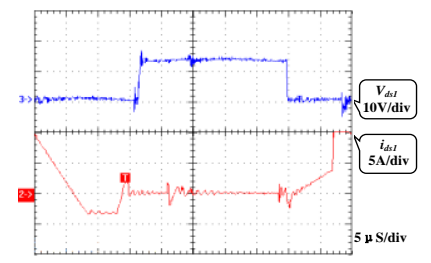

(c) $S_{l}$ switching performance

Fig. 14. Experiment results of voltage regulation performance.

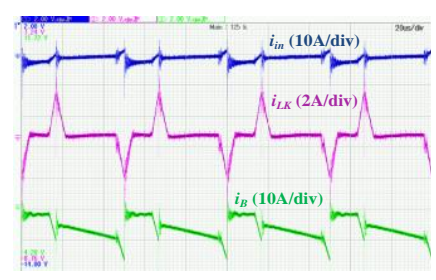

(a) Case $1\left(\varphi=30^{\circ}\right)$ (b) Case $2\left(\varphi=120^{\circ}\right)$
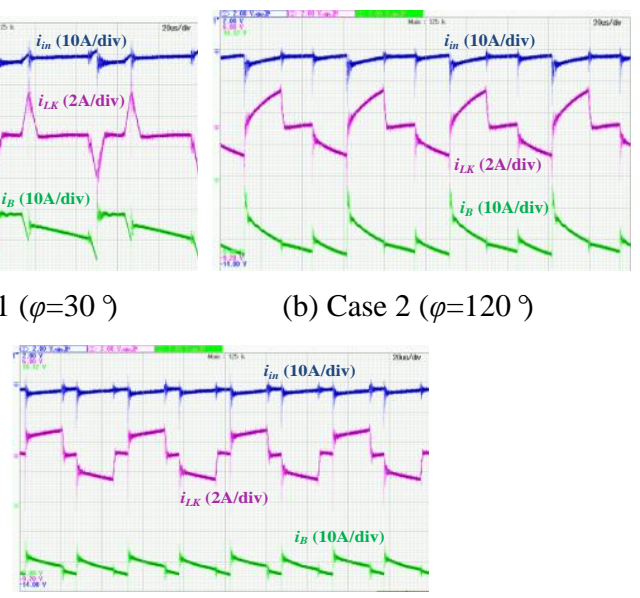

(c) Case $3\left(\varphi=180^{\circ}\right)$

Fig. 15. Current waveforms for different cases ( $D<0.5$ mode 2$)$.

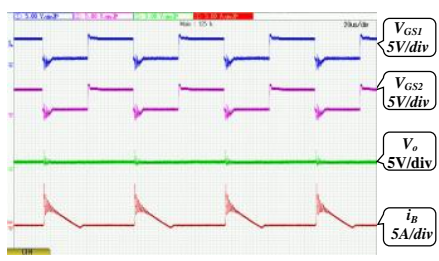

Fig. 16. Steady-state waveforms under mode 3.

Fig. 17 illustrates the measured converter efficiency under mode 1 . It can be seen that the maximum efficiency of this converter is $91.3 \%$ at $200 \mathrm{~W}$ and the rated efficiency is approximately $90 \%$. The power losses at rated conditions are presented in Fig. 17(b). The MOSFET conduction loss and switching loss are $3.1 \mathrm{~W}$ and $6.3 \mathrm{~W}$, respectively, totaling 9.4 $\mathrm{W}$. The power loss in the coupled inductor consists of conduction loss and core loss. The joule loss is $6.1 \mathrm{~W}$ and the core loss is $1.1 \mathrm{~W}$. The diode power loss is $2.9 \mathrm{~W}$. Other power losses are 4.9 W including PCB conduction loss, capacitor equivalent series resistance caused power losses and wire lead power loss. From the break-down of the total power loss, the converter efficiency can be further improved by adopting low-loss switching devices (e.g. GaN), better design of the coupled inductor design, and better packaging design of the converter.

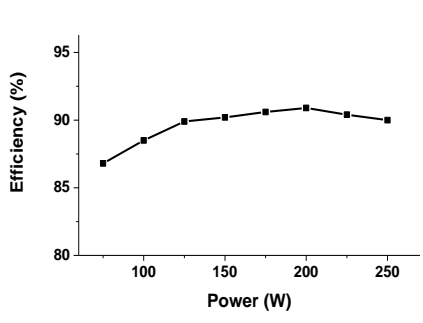

(a) Converter efficiency

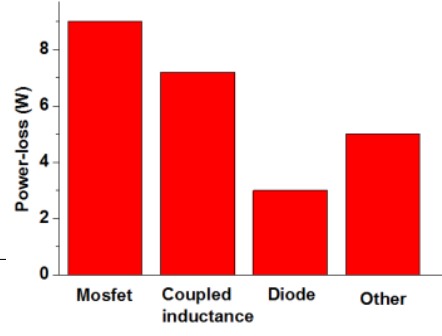

(b) Power-loss analysis
Fig. 17. Experimental results of the converter efficiency and the total power loss. 


\section{CONCLUSIONS}

This paper has presented an isolated three-port DC-DC converter for stand-alone PV systems, based on an improved Flyback-Forward topology. The converter can provide a high step-up capability for power conversion systems including the PV array, the battery storage, and the isolated load consumption. Three operating modes are analyzed and have shown the effective operation of the proposed topology for PV applications. From simulation and experimental tests, it can be seen that the output voltage and PV voltage can be controlled independently by the phase angle shift and PWM, respectively. The decoupled control approach is a simple but effective way to achieve the regulation of output voltage and PV voltage, which is important for MPPT of stand-alone PV systems. In addition, a $250 \mathrm{~W}$ converter is prototyped and tested to verify the effectiveness of the proposed converter topology and control scheme.

The developed technology is capable of achieving MPPT, high conversion ratio and multiple operating modes whist still making the converter relatively simple, light, efficient and cost-effective.

\section{REFERENCES}

[1] K. Basu, N. Mohan, "A high-frequency link single-stage PWM inverter with common-mode voltage suppression and source-based commutation of leakage energy," IEEE Trans. Power Electron., vol. 28, no. 8, pp. 3907-3918, Oct. 2014.

[2] C. Konstantopoulos, E. Koutroulis, "Global maximum power point tracking of flexible photovoltaic modules," IEEE Trans. Power Electron., vol. 29, no. 6, pp. 2817-2828, Oct. 2014.

[3] W. Li, W. Li, X. Xiang, Y. Hu, X. He, "High step-up interleaved converter with built-in transformer voltage multiplier cells for sustainable energy applications," IEEE Trans. Power Electron., vol. 29, no. 6, pp. 2829-2836, Jun. 2014.

[4] Y. Hu, Y. Deng, Q. Liu, X. He, “Asymmetry three-level grid-connected current hysteresis control with varying bus voltage and virtual over-sample method," IEEE Trans. Power Electron. vol. 29, no. 6, pp. 3214-3222, Jun. 2014.

[5] F. Nejabatkhah, S. Danyali, S. H. Hosseini, M. Sabahi,and S. M. Niapour, "Modeling and control of a new three-input DC-DC boost converter for hybrid PV/FC/battery power system," IEEE Trans. Power Electron., vol. 28, no. 10, pp. 4612-4624, Oct. 2013.

[6] F. Zhang, K. Thanapalan, A. Procter, S. Carr, J. Maddy, "Adaptive Hybrid Maximum Power Point Tracking Method for a Photovoltaic System," IEEE Trans. Energy Conversion, vol. 28, no. 2, pp. 353-360, June 2013.

[7] P. Thounthong, "Model Based-Energy Control of a Solar Power Plant With a Supercapacitor for Grid-Independent Applications," IEEE Trans. Energy Conversion, vol. 26, no. 4, pp. 1210-1218, 2011.

[8] A. Elmitwally, M. Rashed, "Flexible Operation Strategy for an Isolated PV-Diesel Microgrid Without Energy Storage," IEEE Trans. Energy Conversion, vol. 26, no. 1, pp. 235-244, 2011.

[9] J. K. Shiau, D. M. Ma, P. Y. Yang, G. F. Wang, and J. H. Gong, "Design of a Solar Power Management System for an Experimental UAV," IEEE Trans. Aerospace and Electronic Systems, vol. 45, no. 4, pp. 1350-1360, Oct. 2009.
[10] F. S. Kang, S. J. Park, S. E. Cho, C. U. Kim, T. Ise, "Multilevel PWM inverters suitable for the use of stand-alone photovoltaic power systems," IEEE Trans. Energy Conversion, vol. 20, no. 4, pp. 906-915, 2005.

[11] H. Valderrama-Blavi, J. M. Bosque, F. Guinjoan, L. Marroyo, and L. Martinez-Salamero, "Power Adaptor Device for Domestic DC Microgrids Based on Commercial MPPT Inverters," IEEE Trans. Ind. Electron., vol. 60, no. 3, pp. 1191-1203, Mar. 2013.

[12] H. Wu, K. Sun, R. Chen, H. Hu, and Y. Xing, "Full-Bridge Three-Port Converters With Wide Input Voltage Range for Renewable Power Systems," IEEE Trans. Power Electron., vol. 27, no. 9, pp. 3965-3974, Sept. 2012.

[13] O. Elma, and U. S. Selamogullari, "A comparative sizing analysis of a renewable energy supplied stand-alone house considering both demand side and source side dynamics," Applied Energy, vol. 96, pp. 400-408, 2012.

[14] H. Wu, R. Chen, J. Zhang, Y. Xing, H. Hu, and H. Ge, "A Family of Three-Port Half-Bridge Converters for a Stand-Alone Renewable Power System," IEEE Trans. Power Electron., vol. 26, no. 9, pp. 2697-2706, Sept. 2011.

[15] Z. Qian, O. Abdel-Rahman, and I. Batarseh, "An Integrated Four-Port DC/DC Converter for Renewable Energy Applications," IEEE Trans. Power Electron., vol. 25, no. 7, pp. 1877-1887, July 2010.

[16] E. Sanchis, E. Maset, A. Ferreres, J. B. Ejea, V. Esteve, J. Jordan, J. Calvente, A. Garrigos, and J. M. Blanes, "Bidirectional High-Efficiency Nonisolated Step-Up Battery Regulator," IEEE Trans. Aerospace and Electronic Systems, vol. 47, no. 3, pp. 2230-2239, Jul. 2011.

[17] K. Shenai, P. G. Neudeck, and G. Schwarze, "Design and technology of compact high-power converters," IEEE Aerospace and Electronic Systems Magazine, vol. 16, no. 3, pp. 27-31, Aug. 2001.

[18] S. Kim, H.-S. Song, and K. Nam, "Idling Port Isolation Control of Three-Port Bidirectional Converter for EVs," IEEE Trans. Power Electron., vol. 27, no. 5, pp. 2495-2506, May 2012.

[19] C. Zhao, S. D. Round, and J. W. Kolar, "An Isolated Three-Port Bidirectional DC-DC Converter With Decoupled Power Flow Management," IEEE Trans.Power Electrons., vol. 23, no. 5, pp. 2443-2453, Sept. 2008.

[20] H. Tao, J. L. Duarte, and M. A. M. Hendrix, "Three-Port Triple-Half-Bridge Bidirectional Converter With Zero-Voltage Switching," IEEE Trans. Power Electron., vol. 23, no. 2, pp. 782-792, Mar. 2008.

[21] J. L. Duarte, M. Hendrix, and M. G. Simoes, "Three-Port Bidirectional Converter for Hybrid Fuel Cell Systems," IEEE Trans. Power Electron., vol. 22, no. 2, pp. 480-487, Mar. 2007.

[22] H. Wu, P. Xu, H. Hu, Z. Zhou, and Y. Xing, "Multi-port Converters Based on Integration of Full-Bridge and Bidirectional DC-DC Topologies for Renewable Generation Systems," IEEE Trans. Ind. Electron., vol. PP, no. 99, pp. 1-1, in press, 2013.

[23] Z. Ouyang, Z. Zhang, M. A. E. Andersen, and O. C. Thomsen, "Four Quadrants Integrated Transformers for Dual-Input Isolated DC-DC Converters," IEEE Trans. Power Electron., vol. 27, no. 6, pp. 2697-2702, June 2012.

[24] L. Wang, Z. Wang, and H. Li, "Asymmetrical Duty Cycle Control and Decoupled Power Flow Design of a Three-port Bidirectional DC-DC Converter for Fuel Cell Vehicle Application," IEEE Trans. Power Electron., vol. 27, no. 2, pp. 891-904, Feb. 2012.

[25] R. J. Wai, C. Y. Lin, and Y. R. Chang, "High Step-Up Bidirectional Isolated Converter With Two Input Power Sources," IEEE Trans. Ind. Electron., vol. 56, no. 7, pp. 2629-2643, July 2009.

[26] W. Li, L. Fan, Y. Zhao, X. He, D. Xu, and B. Wu, "High-Step-Up and High-Efficiency Fuel-Cell Power-Generation System With Active-Clamp Flyback-Forward Converter," IEEE Trans. Ind. Electron., vol. 59, no. 1, pp. 599-610, 2012.

[27] Z. Qian, O. Abdel-Rahman, H. Al-Atrash, and I. Batarseh, "Modeling and Control of Three-Port DC/DC Converter Interface for Satellite Applications," IEEE Trans. Power Electron., vol. 25, no. 3, pp. 637-649, 2010.

[28] P. Bajpai, and V. Dash, "Hybrid renewable energy systems for power generation in stand-alone applications: A review," Renewable and Sustainable Energy Reviews, vol. 16, no. 5, pp. 2926-2939, 2012. 
[29] H. Tao, A. Kotsopoulos, J. L. Duarte, and M. A. M. Hendrix, "Family of multiport bidirectional DC-DC converters," IEE Proc. Electric Power Applications, vol. 153, no. 3, pp. 451-458, May 2006.

[30] B. G. Dobbs, and P. L. Chapman, "A multiple-input DC-DC converter topology," IEEE Power Electronics Letters, vol. 1, no. 1, pp. 6-9, Mar. 2003.

[31] Z. Wang, and H. Li, "An Integrated Three-Port Bidirectional DC-DC Converter for PV Application on a DC Distribution System," IEEE Trans. Power Electron., vol. 28, no. 10, pp. 4612-4624, Oct. 2013.

[32] W. Cai, B. Liu, S. Duan, L. Jiang, "Power flow control and optimization of a three-port converter for photovoltaic-storage hybrid system," Energy Conversion Congress and Exposition (ECCE), pp. 4121-4128, 2012.

[33] Y. M. Chen, X. Yu, A. Q. Huang, "A new nonisolated three-port DC-DC converter with high step-up/down ratio," the 2012 IEEE Energy Conversion Congress and Exposition (ECCE), pp. 1520-1526, 2012.

[34] Q. Wang, J. Zhang, X. Ruan, and K. Jin, "Isolated Single Primary Winding Multiple-Input Converters," IEEE Trans. Power Electron., vol. 26, no. 12, pp. 3435-3442, Dec. 2011.

[35] Y. Li, X. Ruan, D. Yang, F. Liu, and C. K. Tse, "Synthesis of Multiple-Input DC/DC Converters," IEEE Trans. Power Electron., vol. 25, no. 9, pp. 2372-2385, Sept. 2010.

[36] H. Krishnaswami, and N. Mohan, "Three-Port Series-Resonant DC-DC Converter to Interface Renewable Energy Sources With Bidirectional Load and Energy Storage Ports," IEEE Trans. Power Electron., vol. 24, no. 10, pp. 2289-2297, Oct. 2009.

[37] H. Tao, A. Kotsopoulos, J. L. Duarte, and M. A. M. Hendrix, "Transformer-Coupled Multiport ZVS Bidirectional DC-DC Converter With Wide Input Range," IEEE Trans. Power Electron., vol. 23, no. 2, pp. 771-781, Mar. 2008.

[38] W. Li, J. Xiao, Y. Zhao, and X. He, "PWM Plus Phase Angle Shift (PPAS) Control Scheme for Combined Multiport DC/DC Converters," IEEE Trans. Power Electron., vol. 27, no. 3, pp. 1479-1489, 2012.

[39] Yihua Hu, Yan Deng, Jiangtao Long, Xiaoxun Lu, Xiangning He. “A Three-port High Step-up DC-DC Converter for PV System,” ECCE-Asia, Australia, 2013.

[40] W. Xiao, A. Elnosh, V. Khadkikar, and H. Zeineldin, "Overview of maximum power point tracking technologies for photovoltaic power systems," in Proc. Annual Conference on IEEE Industrial Electronics Society, 2011, pp. 3900-3905.

[41] W. Xiao, W. G. Dunford, P. R. Palmer, and A. Capel, "Regulation of Photovoltaic Voltage," IEEE Trans. Industrial Electronics, vol. 54, no. 3, pp. 1365-1374, Jun. 2007.

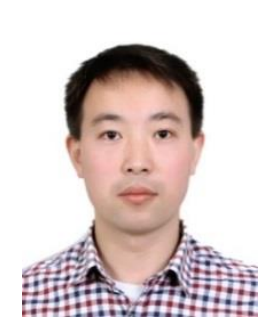

Yihua Hu (M'13) received the B.S. degree in electrical motor drives in 2003, and the Ph.D. degree in power electronics and drives in 2011, both from China University of Mining and Technology, Jiangsu, China. Between 2011 and 2013, he was with the College of Electrical Engineering, Zhejiang University as a Postdoctoral Fellow. Between November 2012 and February 2013, he was an academic Visiting Scholar with the School of Electrical and Electronic Engineering, Newcastle University, Newcastle upon Tyne, UK. He is currently a Research Associate with the Department of Electronic \& Electrical Engineering, University of Strathclyde, Glasgow, UK. $\mathrm{He}$ has published more than 20 technical papers in leading journals and conference proceedings. His research interests include PV generation systems, DC-DC/DC-AC converters, and electrical motor drives.

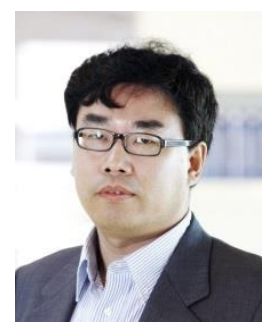

Weidong Xiao (S'04-M'07-SM'13) received the Master degree and the Ph.D. degree from the University of British Columbia, Vancouver, Canada, in 2003 and 2007 respectively. He is an associate professor working with the department of electrical engineering and computer science (EECS) at the Masdar Institute of Science and Technology, Abu Dhabi, UAE. In 2010, he was a visiting scholar with the Massachusetts Institute of Technology (MIT) Cambridge, USA, where he worked on the power interfaces for PV power systems. Prior to the academic career, Dr. Xiao worked with the MSR Innovations Inc. in Canada as a R\&D engineering manager focusing on integration, research, optimization and design of photovoltaic power systems. Dr. Xiao serves as the guest editor for the IEEE Transactions on Industrial Electronics Special Edition on photovoltaic power systems. His research interest includes photovoltaic power systems, power electronics, dynamic systems and control, and industry applications.

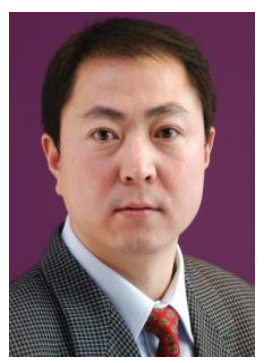

Wenping Cao (M’05-SM'11) (correspondence author) received the B.Eng in electrical engineering from Beijing Jiaotong University, Beijing, China, in 1991; and the Ph.D. degree in electrical machines and drives from the University of Nottingham, Nottingham, U.K., in 2004. He is currently a Senior Lecturer with Queen's University Belfast, Belfast, U.K. He is the recipient of the Best Paper Award at the LDIA'13 Conference. Dr. Cao serves as an Associate Editor for IEEE Transactions on Industry Applications, IEEE Industry Applications Magazine, IET Power Electronics, and nine other International Journals. His research interests are in thermal performance of electric machines, drives and power electronics.

Dr. Cao is also a Member of the Institution of Engineering and Technology (IET) and a Fellow of Higher Education Academy (HEA).

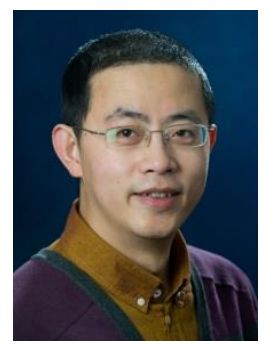

Bing Ji (M'13) received the M.Sc. and Ph.D. degrees in electrical and electronic engineering from Newcastle University, England, in 2007 and 2012, respectively. He was a power electronics engineer with a UK low-emission vehicle company from 2012, where he worked on powertrain development for hybrid electric vehicles and battery management systems. Since 2013, he has been a Postdoctoral Researcher at Newcastle University, where he is involved in accurate power loss measurement and health management for power electronics. His research interests include reliability study of power semiconductor devices, batteries and power electronics converters, function integration of gate drivers, electro-thermal modelng, thermal management and high power-density converter integration for electric vehicle applications. He is also a member of the IET.

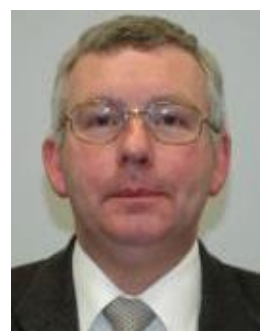

D. John Morrow (M'99) received the B.Sc and Ph.D. degrees from Queen's University Belfast, Belfast, U.K., in 1982 and 1987, respectively. Since 1987, he has been a Lecturer in electrical engineering at Queen's University Belfast, Belfast, U.K., with research interests in electric power systems, power system instrumentation, and embedded generation. Dr. Morrow is a member of the IET and also a member of the IEEE PES Excitation Systems Subcommittee. 